\title{
CUMPRINDO UMA PAUTA DE TRABALHO: CONTRIBUIÇÕES RECENTES DO PEUL
}

\author{
Maria da Conceição de PAIVA * \\ Vera Lúcia PAREDES SILVA**
}

- RESUMO: O grupo PEUL (Programa de Estudos sobre o Uso da Língua) constituiu-se nos anos 80 do século passado, em torno de uma meta comum: a de desvendar a sistematicidade da variação e mudança atestadas na variedade carioca. Inicialmente, mais concentrados na modalidade falada, os estudos ganharam novo fôlego, particularmente do ponto de vista da mudança, com a volta à comunidade de fala cerca de 20 anos mais tarde, o que permitiu a realização de análises da mudança em tempo real de curta duração. Posteriormente, os estudos foram estendidos à escrita monitorada, representada por diversos gêneros do domínio jornalístico. Esta ampliação do corpus permitiu comparar os princípios que regem a variação nas duas modalidades e testar hipóteses relativas à migração/incorporação de mudanças em curso na fala para a escrita. Neste artigo, mostramos de que forma os trabalhos realizados pelos pesquisadores ligados ao grupo contribuíram para alimentar e aprofundar discussões acerca de aspectos relevantes, como a sistematicidade de princípios subjacentes ao uso de formas variáveis, e desvendar o caminho trilhado pelas variantes linguísticas em tempo real e sua incorporação na escrita. Destacamos, ainda, a forma como a colocação contínua de novas questões abriu o espaço para trabalhos na interface com outras áreas do conhecimento.

- PALAVRAS-CHAVE: Sociolinguística. Língua falada. Língua escrita. Gêneros textuais. Aplicações.

\section{Histórico}

O grupo de pesquisa Programa de Estudos sobre o Uso da Língua (PEUL) foi criado no final dos anos 70 por pesquisadores interessados, num primeiro momento, em desvendar a heterogeneidade observada na variedade carioca e depreender os padrões de variação linguística e possíveis mudanças em curso nessa comunidade. Naquele momento, esse objetivo exigia, antes de mais nada, a constituição de uma amostra estratificada da comunidade visada, de forma a identificar a contraparte social da variação e mudanças em curso. Assim, foi

\footnotetext{
* UFRJ - Universidade Federal do Rio de Janeiro. Faculdade de Letras - Departamento de Lingüística. Rio de Janeiro - RJ - Brasil. 21941-917 - paiva@club-internet.fr

** UFRJ - Universidade Federal do Rio de Janeiro. Faculdade de Letras - Departamento de Lingüística. Rio de Janeiro - RJ - Brasil. 21941-917 - veraparedes@terra.com.br
} 
organizado, de forma pioneira no Brasil, um corpus constituído de 64 entrevistas realizadas com falantes cariocas homens e mulheres, distribuídos por quatro faixas etárias e três níveis de escolaridade. Essa amostra representa, ainda, a configuração social diversificada do Rio de Janeiro, ao incluir representantes dos diferentes bairros da cidade e de diversos estratos sociais. ${ }^{1}$

A análise sistemática da Amostra Censo 1980, a partir dos pressupostos centrais da Sociolinguística Variacionista (WEINREICH; LABOV; HERZOG, 2006; LABOV, 1972, 1981, 1982, 1994), tornou possível identificar e explicar fenômenos variáveis nos diversos níveis da língua e levantar hipóteses acerca de mudanças em curso na fala carioca. Processos bem conhecidos, como a variação entre nós/a gente, a variação na concordância de número nos elementos do Sintagma Nominal (doravante SN), a supressão das semivogais nos ditongos decrescentes, a regência variável do verbo ir, a alternância entre seu e dele ou o uso de artigo antes de nomes próprios foram escrutinados, a partir de uma metodologia quantitativa rigorosa, que permitiu depreender a sistematicidade na heterogeneidade, a partir da identificação dos fatores linguísticos associados às diferentes formas de expressar o mesmo conteúdo referencial assim como os padrões de correlação social das variantes. Tais estudos vieram somar evidências favoráveis ou desfavoráveis a princípios mais gerais de variação tanto no eixo linguístico como social. ${ }^{2}$

O corpus, que ficou conhecido como Amostra Censo 1980, foi apenas o começo de outros empreendimentos que permitiram alargar a amostragem da fala carioca. Considerando os limites inerentes às amostras estratificadas para o estudo de aspectos interacionais, entre 1989 e 1990, foi organizado o Banco de Dados Interacionais (BDI), coordenado pela pesquisadora Cláudia Roncarati. Entre 1999 e 2000, com vistas a verificar, em tempo real, hipóteses de mudança indicadas pelos estudos em tempo aparente realizados com a Amostra Censo 1980, empreendeu-se a tarefa de revisitar a comunidade carioca. Duas novas amostras vieram enriquecer o acervo do PEUL: (a) a Amostra Censo 2000, um conjunto de 32 entrevistas realizadas com falantes cariocas, organizada segundo os mesmos parâmetros da Amostra Censo 1980, e (b) uma amostra da fala de 16 indivíduos que já integravam a primeira amostra e foram re-entrevistados. ${ }^{3}$ Associadas, as amostras Censo 1980, Censo 2000 e as entrevistas dos falantes recontactados garantiram (e garantem) o estudo do que Labov $(1981,1994)$ denomina estudo da mudança em tempo real de curta duração, criando as condições ótimas para a verificação mais controlada da direcionalidade de alguns processos variáveis tanto na comunidade de fala (estudo tendência), como no indivíduo (estudo painel).

\footnotetext{
1 Um maior detalhamento sobre a Amostra Censo 1980 pode ser encontrado em Oliveira Silva e Scherre (1996).

2 Essa primeira garimpagem se encontra reunida em Oliveira Silva e Scherre (1996).

3 Maiores detalhes sobre a Amostra Censo 2000 podem se encontrados em Paiva e Duarte (2003).
} 
Uma consequência natural do interesse pela variação e pela implementação da mudança foi o surgimento de questões acerca da forma como novas variantes detectadas na fala são incorporadas pela escrita. Assim, no período de 2002 a 2004, os pesquisadores do grupo organizaram uma amostra da escrita monitorada, composta de textos representativos de diferentes gêneros, publicados em jornais cariocas destinados a um espectro de leitores diferenciado do ponto de vista social (O Globo, Jornal do Brasil, Extra e Povo). Novas hipóteses puderam ser exploradas e tendências mais gerais vieram à luz. ${ }^{4}$

Uma vez delineado um perfil sociolinguístico da variedade carioca, membros do grupo se orientaram para questões concernentes à aquisição da variação estruturada, o que, por si mesmo, requer corpora mais específicos, constituídos de forma a representar diferentes estágios da aquisição da linguagem. O grupo já contava com uma amostra reunida, entre 1979 e 1981, pela professora Alzira V. T. de Macedo, composta de gravações com 32 crianças de 4 a 11 anos. Mais recentemente, sob a iniciativa da pesquisadora Christina Abreu, o grupo se enriqueceu com a organização de outra amostra de dados para o estudo da aquisição da variação socialmente estruturada (AMOSTRA AQUIVAR) representativo da fala de 35 crianças com idade entre 1 ano e 9 meses e 5 anos, de diferentes estratos sociais.

Dadas as limitações inerentes às amostras aleatórias e ao próprio método de coleta de dados utilizado na maioria das amostras, entrevistas sociolinguísticas, diversos pesquisadores vêm lançando mão de amostras mais específicas que possibilitem o estudo de fatos de variação mais particulares, como o caso da amostra constituída por Paredes para o estudo do retorno do pronome tu na variedade carioca (PAREDES SILVA, 2003a, 2011) ou a amostra de Gryner (1990), mais centrada no discurso argumentativo.

Ao longo dos mais de trinta anos em que vem atuando no cenário da Sociolinguística brasileira, o grupo PEUL contribuiu com inúmeros trabalhos voltados para a variação inerente à gramática graças à dedicação de muitos pesquisadores, para quem o uso e a dinâmica da língua estão no centro dos estudos linguísticos. Detalhes relativos à atuação do grupo podem ser encontrados em Paiva e Scherre (1999) e em Scherre e Roncarati (2008).

Procurando estimular a expansão da Sociolinguística no Brasil, os membros do grupo atuam incessantemente na formação de novos pesquisadores, seja no nível de Iniciação Científica, seja nos níveis de Mestrado e Doutorado, que, inseridos no grupo, despertaram ou consolidaram seu interesse pela Sociolinguística Variacionista. A composição do grupo foi se alterando ao longo do tempo, o que

4 As amostras Censo 1980, Censo 2000 e a amostra de textos midiáticos já estão disponibilizadas on-line no site <www.letras.ufrj.br/PEUL>. Atualmente, sob coordenação da professora Conceição Paiva, está sendo preparada a disponibilização dos registros sonoros correspondentes às amostras de fala. 
permitiu não só alargar o círculo de curiosos em relação aos padrões de variação como também abrir novas perspectivas e explorar diferentes interfaces, tais como variação e discurso, variação e aquisição, variação e ensino do português como L1. Os últimos anos se caracterizaram pela abertura de novas frentes de trabalho, explorando a interface com áreas como a da Matemática (LEAL; MOLLICA, 2009, 2010, [20--?]; MOLLICA; LEAL, 2007, 2008, 2010, 2012) ou da Ciência da Informação (MOLLICA; GONÇALEZ, 2012; MOLLICA; LISBOA, 2011), possibilitada pela parceira com outros pesquisadores, especialmente das áreas de Matemática e de Ciência da Informação. Destaquem-se, ainda, os esforços envidados no âmbito da Sociolinguística Educacional, liderado pela pesquisadora Cecília Mollica, no sentido de traduzir os resultados das pesquisas variacionistas em subsídios para a qualificação de professores alfabetizadores e docentes do português como L1.

Naturalmente, o acúmulo de evidências acerca dos padrões de variação e mudança na fala carioca contribuiu de forma significativa para a discussão de diversos pontos que sempre estiveram e continuam na pauta da Sociolinguística Variacionista. Dentre eles, destacamos:

a) Restrições sobre variantes linguísticas podem ser traduzidas em princípios mais gerais?

b) De que formas se inter-relacionam diferentes processos de mudança em curso numa mesma comunidade de fala?

c) Como estabelecer a relação entre mudança na comunidade e mudança no indivíduo? Em outros termos, em que medida a gramática do indivíduo reflete a gramática da comunidade?

d) Qual a trajetória de incorporação pela escrita de mudanças em curso na comunidade de fala? Que princípios norteiam essa incorporação?

e) De que forma os estudos sociolinguísticos podem contribuir para o desenvolvimento de métodos de ensino do português?

Ao longo deste artigo, procuramos sintetizar e discutir, tarefa nada simples, algumas evidências obtidas no trabalho desenvolvido nas diferentes frentes de trabalho, as perguntas que guiaram muitos estudos e algumas respostas encontradas, ao longo desses últimos 12 anos. ${ }^{5}$

\section{Variação e mudança na fala}

O conceito de regra variável, que emerge com os estudos de Labov (1972), representou um avanço teórico importante para a ciência linguística, na medida

Para uma retrospectiva de trabalhos desenvolvidos até o ano de 1999, ver Paiva e Scherre (1999). 
em que incorpora à gramática a sistematicidade estrutural e social do componente variável da língua. O investimento constante nessa vertente de estudos por diferentes pesquisadores do PEUL tem acumulado evidências consideráveis sobre (a) a configuração de vários fenômenos variáveis no português falado no Rio de Janeiro, (b) as restrições que operam sobre cada um deles, (c) a ação regular dos diferentes princípios que subjazem ao uso das formas variáveis e regulam a implementação da mudança na comunidade de fala e no indivíduo.

Nesta seção nos detemos em aspectos relativos à mudança, a partir dos resultados obtidos com estudos em tempo real de curta duração. A análise detalhada de fenômenos variáveis distintos na comunidade de fala carioca, através da comparação das amostras Censo 1980 e Censo 2000, e da mudança no indivíduo, através da comparação das entrevistas realizadas com o mesmo falante nos anos oitenta e no começo deste século, tornou possível depreender três trajetórias distintas no percurso de algumas variantes linguísticas já identificadas com base na amostra Censo 1980: (a) contínua implementação de variantes linguísticas; (b) estabilidade da variação e (c) retração de uma variante em contextos particulares. A primeira possibilidade pode ser ilustrada pela realização variável da preposição núcleo dos complementos dativos, instanciada como: a, para ou zero, focalizada por Gomes (2003). A autora comprova o aumento da preposição para, na comunidade de fala, em todas as faixas etárias, ocupando mesmo contextos que, no início da década de 80, eram exclusivos da preposição a. Tal generalização se deve, segundo a autora, ao caráter mais neutro dessa preposição em oposição, por um lado, à formalidade da preposição a e, por outro, a um certo estigma associado à ausência da preposição.

A tendência de estabilidade encontra ilustração na variação entre variante plena e variante nula na realização do sujeito, fenômeno focalizado por Duarte (1995, 2003a) e Paredes Silva (2003b). Embora partindo de perspectivas teóricas distintas, as duas pesquisadoras mostram índices equivalentes de sujeito preenchido nas duas amostras, sem alterações significativas ao longo do tempo. Situação similar é encontrada por Omena (2003) para a alternância entre nós e a gente, no estudo do tipo tendência. Destaque-se que essa tendência de estabilidade é, segundo as indicações depreendidas em tempo real de curta duração, independente do possível estigma social da variante focalizada, como mostra o trabalho de Mollica (2003b) para as relativas copiadoras.

A terceira possibilidade, regressão de uma variante, é detectada por Paiva (2003) para a supressão da semivogal [y] no ditongo decrescente [ey]. O processo é particularmente favorecido em dois contextos: o de flap (feira/fera) e de consoantes palatais (beijo/bejo). Analisando os dois contextos separadamente, a autora atesta direções contrárias para cada um deles: no contexto de flap, o processo se configura como mudança concluída; no contexto de palatais, ao 
contrário, a taxa de monotongação de [ey] se reduz sensivelmente. Tal situação sinaliza a necessidade de uma análise mais fina dos contextos de implementação da mudança e permite colocar em causa o princípio de que uma mudança opera unicamente por um aumento constante de taxas em todos os contextos em princípio favoráveis.

Ademais, esses estudos trazem evidências robustas para a discussão das relações entre a mudança na comunidade e no indivíduo, uma questão central no estudo da mudança. Assim, Paiva (2003), por exemplo, mostra que a tendência à redução do processo de supressão de [y] no contexto de palatal se reflete de forma diferenciada no comportamento dos 16 indivíduos recontactados no final de década de noventa e no início de 2000. Se a grande maioria dos falantes se conforma ao recuo na redução de [ey] nesse contexto, uma pequena parte tende a se manter estável ou aumenta o índice da variante monotongada. Falantes mais inovadores convivem, portanto, com falantes mais conservadores.

Uma situação semelhante é verificada por Omena (2003) para a alternância entre nós e a gente, um processo para o qual as evidências diacrônicas de mudança são mais seguras. Alguns falantes manifestam larga implementação de a gente, alcançando uso categórico dessa variante. Observa-se, no entanto, nítida divergência na trajetória de a gente quando se consideram os indivíduos que variam. Apenas seis, do total de dezesseis falantes recontactados, apresentam, como se poderia esperar, aumento nas taxas de a gente e alguns falantes, surpreendentemente, aumentam o uso de nós. Tais evidências permitem problematizar o princípio sustentador da análise da mudança em tempo aparente, ou seja, o de estabilidade do sistema linguístico adquirido até a adolescência (LIGHTFOOT, 1999). Se tomarmos como base a alternância entre nós e a gente para a expressão da $1^{a}$ pessoa do plural, essa hipótese poderia ainda se manter, com base no argumento de que o uso de uma ou outra variante afeta unicamente os dados primários a que são expostos os indivíduos sem alterar a gramática nuclear. A maior resistência a mudanças que envolvam a gramática nuclear encontra evidências nos resultados encontrados por Duarte (2003a) para o preenchimento do sujeito. No caso em questão, uma possível mudança na marcação do parâmetro do sujeito nulo, observa-se convergência acentuada no comportamento do indivíduo e da comunidade. A questão permanece, portanto, em aberto e requer evidências de outros fenômenos relacionados a essa mudança em progresso, que serão brevemente referidos ainda nesta seção.

A própria metodologia e as conclusões autorizadas pelos agrupamentos etários, em estudos do tipo tendência, podem obscurecer aspectos da relação entre mudança no indivíduo e na comunidade. Os estudos desenvolvidos mais recentemente pelos pesquisadores Anthony Naro e Marta Scherre sobre a concordância nominal e a concordância verbal vão nesta direção. Os primeiros 
estudos em tempo real de curta duração fornecem indícios claros de aumento das marcas de concordância verbal e nominal tanto no indivíduo como na comunidade de fala carioca (NARO; SCHERRE, 2003, 2010). Reexaminando essa tendência mais recentemente (SCHERRE; NARO, 2011), os dois autores retomam a questão do efeito de variáveis sociais sobre a presença das marcas de concordância entre verbo e sujeito e em todos os elementos do SN, na comunidade de fala carioca, com o intuito de evidenciar como os grupos de falantes mudam no tempo. Os autores ponderam que a própria metodologia de análise do efeito da variável tempo, baseada na comparação direta de grupos semelhantes, pode não ser a forma mais adequada de apreender padrões de mudança no interior de uma comunidade, porque os indivíduos que compõem os conjuntos (grupos etários, por exemplo) não são os mesmos. Segundo a análise dos autores, uma reorganização dos grupos etários permite identificar, de forma mais clara, os padrões de distribuição de variantes linguísticas por diferentes grupos etários.

As faixas etárias das amostras Censo 1980 e Censo 2000 foram previamente organizadas em quatro grupos: 7-14 anos, 15-25 anos, 26-49 anos e acima de 50 anos. Considerando o intervalo de tempo que separa as duas amostras, os autores redistribuíram os falantes, deslocando a amostra Censo 1980 dezoito anos, para comparar grupos etários mais diretamente comparáveis (age cohorts), extraídos dos mesmos universos etários.

Essa reorganização fornece indícios mais claros de que, embora todos os grupos etários tenham aumentado sua frequência de marcas de concordância, o padrão de correlação já observado, na amostra Censo 1980, para cada um dos fenômenos de concordância, se mantém na segunda sincronia: gradação etária para a concordância nominal e perda na concordância verbal. Essa similaridade é indicativa de que os falantes de todas as idades se movem, mas sujeitos às restrições impostas por padrões sociais do grupo em que estão inseridos. O padrão é claramente modificado somente para os falantes que ainda não haviam nascido na década de 80, que reverteram seu comportamento em direção a maior uso de concordância, com percentuais e pesos relativos mais altos.

Usando os agrupamentos de idade projetados no lugar das faixas etárias originalmente estabelecidas, Naro e Scherre (2011) puderam, então, ver mais claramente as mudanças dentro da comunidade de fala e confirmar tanto o modelo de fluxos e contrafluxos, proposto inicialmente por Naro (1981) e retomado por Naro (1999) e Naro e Scherre (2010), como a ampliação da aquisição da concordância do plano individual para a comunidade como um todo. Testemunha-se, assim, a previsão de Naro (1981), baseada na análise da Amostra MOBRAL ${ }^{6}$ (NARO, 1981), no que diz respeito ao efeito da variável

6 A amostra denominada MOBRAL é um conjunto de entrevistas gravadas com 20 falantes em processo de alfabetização no início da década de 70 e que participavam dos cursos oferecidos pelo Movimento Brasileiro de 
orientação cultural sobre a concordância verbal. Os falantes que se identificavam com valores da classe média, os de orientação vicária, favoreciam mais a concordância verbal. Este traço foi mensurado por meio do tipo de programa de televisão visto, no caso, as novelas. Assim, Naro (1981) levanta a hipótese de que este efeito no plano individual poderia ser ampliado para a comunidade por meio das faixas etárias mais jovens, que é o que estamos observando nos dados do PEUL da década de 2000.

Um estudo do tipo painel confirma a tendência identificada no estudo da comunidade (NARO; SCHERRE, 2011). Considerando cada um dos momentos de tempo (década de 1980 e década de 2000) como uma variável independente para cada falante, os autores concluem que, num intervalo entre 16 e 18 anos, todos os falantes aumentaram os seus índices de concordância, embora em magnitudes distintas. Essa tendência é, em parte, independente de o falante ter aumentado ou não o seu nível de escolaridade. No entanto, aqueles que o aumentaram, apresentam um ganho sistemático e mais contundente de concordância. Constatam, ainda, que o aumento da concordância nominal entre falantes que não mudaram o nível de escolarização era menos saliente do que o aumento de concordância verbal, interpretado pelos autores como possível consequência da configuração linguística de cada um dos fenômenos e das restrições resultantes da saliência fônica: itens de oposição singular/plural mais salientes são mais frequentes na concordância verbal, o que propicia a sua maior percepção.

A concordância nominal, por sua vez, um tanto paradoxalmente, separa mais nitidamente os indivíduos em função da escolarização. Os autores interpretam este fato como fruto de a concordância nominal apresentar uma relação sintagmática menos complexa, entre elementos de um mesmo sintagma, e facilitar, assim, sua maior generalização em áreas urbanas, quando percebida. Tudo leva a crer, portanto, que, na variedade urbana carioca, aspectos cognitivos operam juntamente com aspectos sociais, intensificando seu efeito por meio de dimensões estruturais que operam sobre a variação e a mudança. Interpretações à parte, é fato indubitável que a análise em tempo real de curta duração revela o aumento da concordância de número, variável que envolve estigma social.

O que se destaca nos diversos estudos em tempo real de curta duração é a sistematicidade no controle estrutural da variação. O já citado estudo de Paredes Silva (2003b), por exemplo, demonstra claramente a primazia da variável conexão discursiva nas chances de preenchimento do sujeito, nos dois momentos de tempo considerados. O preenchimento do sujeito, regularmente nas duas sincronias, está nitidamente correlacionado a uma escala no grau de conexão entre as duas

Alfabetização. Neste estudo, Naro (1981) verificou que os falantes que se identificavam mais com os valores da classe média, os de orientação vicária, revelavam maior uso de concordância verbal. Este fato foi mensurado por meio do tipo de programa visto, no caso, as novelas. 
orações: quando maior o estreitamento sintático-discursivo entre as orações (caso de persistência de um referente na mesma função sintática e sem mudança de tópico ou de plano discursivo), maior a probabilidade de apagamento do SN sujeito.

Essa regularidade no efeito de fatores estruturais pôde ser constatada igualmente em fenômenos socialmente estigmatizados, como é o caso das relativas copiadoras ou da concordância nominal e verbal. Como confirma Mollica (2003b), a retomada do constituinte relativizado por um pronome é controlada pelo traço [+humano] do referente: referentes com o traço [+ humano] aumentam as chances de uma relativa copiadora. No caso da concordância nominal e verbal destaca-se, por exemplo, o efeito regular de variáveis como saliência fônica, posição relativa, paralelismo discursivo e paralelismo oracional, além do traço humano para a concordância verbal (NARO, 1999; NARO; SCHERRE, 2003; SCHERRE, 2010). Essa sistematicidade é notável igualmente em fenômenos que envolvem uma nítida contraparte discursiva, como é o caso da variação entre futuro do subjuntivo e o presente do indicativo na construção condicional. Como mostra Gryner (2003), de forma regular nas duas amostras, destaca-se nitidamente a correlação entre uma escala epistêmica e o uso do futuro do subjuntivo ou do presente do indicativo: a primeira variante é significativamente mais recorrente em orações condicionais que codificam um fato possível ou eventual.

Esta constância no efeito de variáveis estruturais conduz a uma discussão mais aprofundada da forma como princípios mais gerais e de natureza distinta operam sobre a variação e a implementação de mudanças linguísticas. Retomemos, a título de exemplo, a variável traço de animacidade do referente que, como vimos acima, possui um efeito saliente tanto sobre as relativas copiadoras como sobre a concordância verbal. Diferentes trabalhos fazem sobressair o alcance explicativo desta propriedade na implementação de mudanças linguísticas e permitem, inclusive, explicar um dos pontos centrais de uma teoria da mudança, qual seja, o do encaixamento entre fenômenos aparentemente distintos, como mostram os estudos de Duarte, inseridos em uma perspectiva da Sociolinguística Paramétrica. Procurando identificar os efeitos colaterais da mudança que envolve a forma de realização do sujeito no português brasileiro, ou seja, a mudança na marcação do valor do parâmetro de sujeito nulo, a autora persegue a hipótese de que diversas mudanças em curso no PB podem ser explicadas em termos de uma hierarquia referencial, construída a partir de evidências empíricas (CYRINO, 1997; DUARTE, 2000; CYRINO; DUARTE; KATO, 2000). Considerando a expressão do sujeito, a autora assume que a mudança se implementa com maior velocidade a partir dos itens mais referenciais, aqueles com o traço inerentemente [+humano] $\left(1^{a}\right.$. e $2^{a}$. pessoas), prossegue mais lentamente naqueles em que interagem os traços [+/-humano], [+/-específico] (a $3^{\mathrm{a}}$. pessoa) e naqueles em que o sujeito retoma uma proposição (DUARTE, 2003a, 2012). Trata-se de sujeitos neutros, 
nulos ou retomados por um demonstrativo, ou de "referência estendida" nos termos de Paredes Silva (1985) ${ }^{7}$. Por remeterem a porções maiores do texto, se situam em um ponto de menor referencialidade. No extremo do continuum de referencialidade, aparecem os sujeitos não referenciais, das chamadas sentenças impessoais, que permanecem nulos no português, embora sejam preenchidos por um expletivo em outras línguas que passaram pelo mesmo processo de mudança (DUARTE, 2003b, 2007b).

O estudo de outros fenômenos tem permitido ressaltar a importância de princípios de natureza mais funcional, como os princípios de marcação ou de iconicidade, ou de princípios relativos ao processamento na retração/expansão de mudanças linguísticas na fala, e mesmo na escrita, como veremos na seção seguinte.

A generalidade de princípios ligados a processamento é comprovada pela sua ação sobre fenômenos bastante diferenciados, como o de concordância verbal e nominal, o uso de relativas copiadoras, a posição de constituintes circunstanciais, a retomada do sujeito por um pronome, entre outros. O efeito de paralelismo discursivo, por exemplo, é amplamente comprovado e discutido por Scherre (1998) e por Scherre e Naro (1992) para os fenômenos de concordância nominal e verbal. Destaca-se, ainda, em trabalhos que focalizam alternâncias entre formas verbais, como o de Costa (2003), Tesch (2011) e Martins (2010).

Paiva et al. (2009) e Paiva (2008b) demonstram, de forma clara, as restrições impostas por um princípio de peso final (PAIVA, 2008b, 2012) sobre a disposição sintagmática de circunstanciais locativos e temporais: tendem a ocupar a margem direita da oração os constituintes circunstanciais de maior peso, ou seja, mais extensos. A restrição de que constituintes menores precedem constituintes mais extensos é mostrada ainda mais claramente nas orações em que concorrem circunstanciais de categorias semânticas distintas, como as de tempo, modo e lugar. O princípio de peso final explica uma quantidade maior da variação do que exigências decorrentes de dependência sintático-semântica. A ação desse princípio sobre constituintes argumentais pode ser atestada, por exemplo, no estudo de Gomes et al. (2003) acerca da variação na ordem dos complementos dos verbos de três argumentos.

O efeito regular de um fator como distância em diferentes fenômenos sinaliza igualmente a relevância de princípios cognitivos. O estudo das relativas copiadoras, por exemplo, mostra claramente que o referente relativizado é mais frequentemente copiado quando há maior distância entre o referente retomado e o pronome relativo. No caso dos sujeitos duplos, ou deslocamento à esquerda do sujeito, observase tendência similar (BRAGA; MOLLICA, 2010). É significativo igualmente na

Sujeitos que retomam uma extensão maior de texto, ou seja, uma oração ou mesmo um parágrafo e que podem ser expressos pelo pronome neutro isso ou pela anáfora zero, ou mesmo por um nome que funciona como rótulo ou encapsulador. 
alternância entre formas nominais/pronominais nos processos de referenciação que envolvem continuidade tópica (PAREDES SILVA, 2007a, 2007b, 2008a, 2008b).

As questões colocadas até este ponto envolvem fenômenos que se conformam, pelo menos aparentemente, a uma definição de variável linguística no seu sentido laboviano clássico, isto é, a alternância entre duas ou mais formas referencialmente equivalentes. Alargando o conceito de variação, podemos recobrir igualmente casos em que uma "mesma" forma pode corresponder a significados distintos, mais importante ainda, estatutos categoriais diferentes. Desse modo, é possível tratar nos moldes da Sociolinguística Variacionista os processos de gramaticalização, isto é, mudanças em que uma mesma palavra ou construção pode sofrer, a par das mudanças semânticas e gramaticais, um desgaste em sua forma fônica. Esse tipo de variação tem despertado atenção particular de alguns pesquisadores do grupo PEUL, sendo estudado tanto na sua dimensão diacrônica como sincrônica. Ilustrações da aplicabilidade de métodos variacionistas a fenômenos dessa natureza são fornecidas pelos estudos de Braga (2003), acerca da trajetória dos itens aí e então no indivíduo; de Roncarati (2003, 2010), sobre as formas demonstrativas, especialmente a discursivização da forma isso; de Paiva (2001), sobre a gramaticalização da locução por causa de que como um conector causal, e o de Paiva e Barros (2011), sobre as construções modais ter que + infinitivo e ter de + infinitivo. Esses estudos procuram identificar as propriedades distintivas deste tipo de mudança e têm contribuído para a discussão de princípios como o da unidirecionalidade. Alguns trabalhos que procuram explicar o continuum sincrônico nos usos de uma mesma forma como resultado de um longo processo diacrônico (BRAGA, 2003) têm apontado que nem sempre há uma correspondência exata entre a pressuposta unidirecionalidade sincrônica e a verificada unidirecionalidade diacrônica.

Mais recentemente, esses estudos têm procurado fomentar o diálogo entre pressupostos teóricos da gramaticalização e da gramática de construções, enfatizando as restrições e motivações cognitivas capazes de explicar os processos de mudança categorial. Uma exemplificação desse diálogo pode ser encontrada nos trabalhos de Braga e Paiva (2011a, 2011b), em que as autoras traçam a diacronia das construções causais, mostrando as inter-relações entre elas ao longo dos três últimos séculos. Nessa abordagem, ganham destaque, ainda, questões ligadas à frequência de tipo (type) e de ocorrência (token) e seus efeitos sobre a representação das categorias gramaticais.

As tendências ressaltadas até este ponto são depreendidas a partir da análise de amostras estratificadas, que, embora permitam conclusões seguras acerca de padrões de correlação entre a estrutura linguística e a organização social, impõem limitações à análise de aspectos ligados, por exemplo, à inserção do falante em redes sociais (MILROY, 1980) e de processos como o de acomodação linguística, 
que ganha vulto numa megalópole como o Rio de Janeiro, em que convivem falantes de diferentes origens geográficas. O investimento nessa vertente, através de trabalhos realizados pela pesquisadora Cecília Mollica, tem permitido trazer à luz a forma como esses falantes acomodam características do seu dialeto de origem e o consequente surgimento de novas variantes linguísticas. Além disso, vem fomentar a discussão de questões concernentes a atitudes e crenças linguísticas, resistência e assimilação, orientação para a identidade ou para o prestígio (LABOV, 1972).

\section{Variação e mudança na escrita}

Como já foi dito na introdução deste artigo, no período de 2002-2004 os pesquisadores do grupo PEUL se dedicaram à constituição de um acervo de língua escrita em que se contemplaram diversos gêneros do domínio jornalístico. O objetivo era, com base nesse corpus, investigar, de forma sistemática, fenômenos variáveis já analisados na fala do Rio de Janeiro, em uma amostra que podemos caracterizar como um padrão de escrita vigente na época. Ao mesmo tempo, a destinação a um público-leitor diferenciado8 permitiria avaliar até que ponto haveria correlações de ordem social no uso de uma modalidade de língua, de qualquer forma, mais monitorada do que a fala de nossas entrevistas.

As análises deste material foram orientadas por várias questões, destacandose dentre elas:

(a) Estaria, de fato, a variação na escrita correlacionada às mesmas restrições encontradas na fala?

(b) Até que ponto as diferenças decorrentes do meio de produção poderiam se refletir nos efeitos associados às variáveis estruturais?

(c) Considerando-se fala-escrita como um continuum, qual a interferência dos diferentes gêneros textuais nos processos de variação e mudança? Admitindo que a migração de processos de mudança para a escrita seja gradativa, quais os gêneros de maior receptividade às formas da oralidade? Que princípios mais gerais subjazem a essa migração?

(d) A constância de alguns efeitos na fala e na escrita, ainda que com um peso diferente, permite estabelecer a existência de princípios de ordem mais geral, e mesmo universal, para a variação e mudança linguísticas?

(e) Que contribuições essas novas análises poderiam representar para aqueles que se dedicam ao ensino da língua materna e à formação de professores?

8 O público-alvo foi determinado em função do preço do jornal nas bancas. 
Fenômenos como o preenchimento variável do sujeito (referencial e arbitrário), o uso variável do dativo, o queísmo e o dequeísmo, a expressão variável das relativas, a ordenação de circunstanciais temporais e locativos, a expansão de uso da forma onde e a variação na concordância verbal foram alguns dos aspectos examinados em estudos comparativos, cujos resultados estão reunidos em número temático da Revista LinguíStica, do Programa de Pós-Graduação da UFRJ (2007), e em volume organizado por Paiva e Gomes ([20--]). Em linhas gerais, tais trabalhos confirmaram uma escrita bem mais conservadora do que a fala, apesar de deixarem transparecer alguns aspectos inovadores, com gradativa incorporação de formas linguísticas frequentes na oralidade.

A face mais conservadora da escrita se expressa, por exemplo, na preservação de formas e estruturas praticamente extintas, ou em franco processo de desaparecimento na fala, como é o caso das formas de expressão do sujeito arbitrário, estudadas por Duarte (2007b) e Duarte e Freire ([20--]). Tais trabalhos mostram que, embora os textos jornalísticos em muito se aproximem dos textos orais no que diz respeito, por exemplo, ao controle estrutural do sujeito preenchido, as duas modalidades se distinguem nitidamente quanto às formas preferenciais de expressão do sujeito de referência arbitrária: na escrita, ainda prevalecem o se indeterminador e o uso da terceira pessoa do plural, em oposição à ampla disseminação de formas de indeterminação através de pronomes como você e a gente na fala (SANTOS, 2003).

A natureza mais conservadora da escrita não impede, no entanto, que formas mais próprias da modalidade oral encontrem guarida nos textos escritos, mesmo naqueles de maior formalidade. Mollica et al. (2007) detectam a presença de fenômenos como a ocorrência de pausa entre sujeito e verbo, refletida no uso da vírgula; a omissão da preposição diante do conectivo que (o chamado queísmo); e a ocorrência da relativa cortadora em textos jornalísticos, principalmente naqueles de feição mais popular. Comparando a escrita jornalística com redações de alunos de um vestibular comunitário, constata-se maior presença das formas menos padrão na produção escrita dos segundos, mostrando que os filtros normativos operam de forma diferenciada em diferentes gêneros textuais.

As pressões de caráter prescritivista não conseguem impedir a migração de variantes não previstas pela norma, quando se trata de variações que envolvem mudança, como é o caso do queísmo e das relativas cortadoras (MOLLICA, 2008). Mesmo em gêneros mais formais e supostamente mais monitorados, como dissertações e teses de áreas distintas como Letras/Linguística e Ciências Exatas, pode ser atestada a presença dessas construções, como evidencia Mollica (2010). Comparando um largo período de tempo, que compreende desde a década de 60 do século passado até os dias atuais, a autora conclui que, a partir dos idos de 80, tais estruturas encontram porta aberta na escrita de textos acadêmicos, sem distinção 
de área de conhecimento. Trata-se, sem dúvida, de inovação importada da fala, modalidade em que tais usos, possivelmente, têm avançado nos últimos decênios.

Adotando uma perspectiva funcionalista, associada ao conceito de marcação, a autora atribui a migração dessas estruturas para a escrita ao fato de elas serem menos complexas, com menor custo de produção - e desse ponto de vista menos marcadas, o que permite que a diferença entre elas e a padrão passe despercebida ao falante.

Inovação também presente na escrita é o uso de onde, em variação com prep. + art. + QU. Originalmente um relativo de valor locativo, este elemento passa a ser usado em remissões anafóricas a categorias não locativas (BRAGA et al., 2007). Os autores apresentam evidências de ordem diacrônica que permitem interpretar essa evolução como um processo de gramaticalização de onde, como conector, que vai se afastando do seu valor espacial e perde suas propriedades anafóricas, no caso a necessidade de antecedente, própria dos relativos. Utilizando para a escrita uma perspectiva diacrônica, os autores comprovam a expansão do uso não padrão em ambas as modalidades, porém com pesos relativos diferentes, e atestam o papel diferenciado da categoria cognitiva do termo retomado (espaço, objeto, instituição, pessoa etc.) particularmente na escrita. Destacam a necessidade de se considerarem os diferentes gêneros e tipos textuais em análises dessa natureza, em ambas as modalidades.

O que se destaca em muitos trabalhos é que a trajetória de incorporação de formas da oralidade envolve o continuum de gêneros textuais, comprovando, assim, a fragilidade de uma dicotomização entre fala e escrita. Pode-se afirmar que um dos principais ganhos da amostra jornalística decorreu da sua abrangência, levando-se em conta diferentes gêneros veiculados na imprensa escrita. Essa diversificação permitiu aos pesquisadores examinar mais minuciosamente a correlação entre variantes linguísticas e diferentes "formas estáveis de enunciado" (BAHKTIN, 2003), que poderiam passar despercebidas numa oposição dicotômica fala/escrita e atestar que a porta de entrada para estruturas mais características do oral são os gêneros textuais mais informais ou que se situam num ponto mais intermediário do continuum fala-escrita.

O estudo de Gomes sobre a variação no uso do dativo anafórico (2007, [20-]), por exemplo, revela tendências inovadoras na escrita como a substituição da preposição a, prototípica dos complementos dativos, pela preposição para, de natureza mais informal e em estágio avançado de implementação na fala, como vimos na seção 1. Essa substituição ocorre com mais frequência, no entanto, nos gêneros jornalísticos em que o leitor é diretamente referido, como o horóscopo, o que lhes confere uma maior aproximação com a oralidade. A variante ausência de preposição, mais estigmatizada socialmente (dei $\varnothing$ ele o livro), é de fato evitada na escrita jornalística, tendo ocorrido apenas num caso isolado. 
A importância da variável gênero é notável também na alternância entre SN, pronome e anáfora zero para a expressão do sujeito de terceira pessoa, como mostra Paredes Silva (2007b). Sua análise revela um crescendo na preferência pelo SN nos gêneros jornalísticos analisados, em proporção direta ao aumento no grau de formalidade do texto. Assim, numa comparação entre artigos de opinião, notícias e crônicas, são os dois primeiros que mais utilizam a variante nominal. Para a autora, tal tendência se explica com base em princípios funcionalistas, como a informatividade, ou seja, a necessidade de deixar claro para o leitor o tópico/tema tratado, seja por repetição do termo ou por recategorização do referente. Além disso, aspectos como a distância referencial e o traço semântico de animacidade são variáveis também correlacionadas a essas preferências. Expondo ideias, portanto, num plano inanimado, os articulistas optam pela retomada nominal. Esta tendência vai ao encontro de resultados já observados na análise da escrita informal de cartas pessoais (PAREDES SILVA, 1988), em que se constatou que a escolha do pronome no português é fortemente associada ao traço de animacidade do referente.

No gênero crônica, considerado o mais informal entre aqueles analisados, prevalece a norma de uso da anáfora zero em contextos de continuidade referencial (PAREDES SILVA; COSTA PINTO, 2010), o que vai ao encontro da tendência depreendida para a fala, como foi destacado na seção 1 (PAREDES SILVA, 2003b).

A precedência da anáfora zero sobre outras formas de realização do sujeito em textos de maior formalidade é corroborada no estudo dos denominados sujeitos de referência estendida (seção 2), como atestam Paredes Silva e Oliveira ([20--]). Comparando diferentes gêneros de escrita, desde cartas pessoais até gêneros jornalísticos mais formais (editoriais), as autoras constatam maior conformidade dos gêneros editorial e artigo de opinião à orientação normativa, com maior recorrência da anáfora zero, se comparados, por exemplo, a gêneros mais informais como a carta pessoal.

A ordenação de SPreps circunstanciais temporais e locativos, investigada por Paiva (PAIVA et al., 2007; PAIVA, 2008a, 2008b, 2011, [20--]) à luz do conceito de marcação, é outro exemplo da necessidade de olhar as diferenças entre fala e escrita sob o prisma de um continuum de gêneros textuais. Focalizando apenas os SPreps temporais (PAIVA et al., 2007), as autoras depreendem diferenças atribuíveis às condições de produção da fala e da escrita. Em linhas gerais, a produção mais planejada da escrita e a sua forma de recepção propiciam disposições sintagmáticas (como a "intromissão" do circunstancial entre um verbo e seu argumento) evitadas na fala, cujo processamento se faz on-line. Comparando, no entanto, diferentes gêneros (editoriais, notícias/reportagens ${ }^{9}$

9 Neste artigo, não estamos fazendo distinção entre notícias e reportagens, embora reconheçamos que haja, no âmbito jornalístico, necessidade de fazê-lo. Como nosso material se restringiu às notícias da cidade, o que 
e crônicas) a autora constatou que são os editoriais o gênero jornalístico mais propenso a situar os circunstanciais temporais na periferia esquerda da oração. As reportagens, por sua vez, se destacam como o gênero que mais evita esse uso, provavelmente em razão de serem mais centradas nos participantes, que garantem a continuidade referencial através do sujeito/tópico principal. Ora, essa diferença de comportamento observada nos gêneros reforça uma discussão teórica já empreendida por vários autores (GIVÓN, 1990; CROFT, 1990; DRYER, 1995) quanto à relatividade do conceito de marcação, quando se levam em conta diferentes formas de organização textual.

A questão da correlação forma-função, entendida em termos de efeitos discursivos e pragmáticos, e gênero discursivo vai aparecer sobremaneira nos estudos de Roncarati (2003, 2008, 2009, 2010), tanto naquele voltado para o uso de estruturas clivadas na escrita como nos que focalizam a referência demonstrativa ou a construção da dêixis social. Destaca-se para esses diferentes fenômenos linguísticos o papel de variantes linguísticas na construção argumentativa do texto. Analisando textos acadêmicos, Almeida e Roncarati (2007) ressaltam o papel dessas estruturas na construção da proeminência informativa e sua contribuição para a orientação da leitura. Na análise das diferentes formas de tratamento (pronome de tratamento, vocativo, expressões referenciais definidas ou indefinidas), Roncarati (2008) mostra que as formas de tratamento mais frequentes em cada um dos gêneros analisados (reportagem, artigo de opinião, cartas de leitores, editoriais, colunas sociais) são colocadas a serviço de objetivos comunicativos, singularizando uma orientação argumentativa. ${ }^{10}$

Duas perguntas instigam os estudos sobre a variação e mudança na escrita: a primeira diz respeito à convergência no efeito de variáveis estruturais; a segunda concerne à generalidade de princípios que autorizam a migração de variantes linguísticas inovadoras para a escrita. A primeira pode encontrar resposta positiva na regularidade do controle estrutural da variação em ambas as modalidades, ainda que com diferenças na magnitude dos efeitos. Os já citados trabalhos de Duarte e o de Paredes Silva sobre a forma de realização do sujeito chegam a conclusões semelhantes: destaca-se também na escrita a importância da relação do sujeito sob análise com sua menção prévia (tratada como condições de referência em Duarte (2003a) e como distância referencial em Paredes Silva (2007b) ou conexão discursiva em Paredes Silva (1988, 2003a). O traço de animacidade do sujeito, um forte promotor do uso do pronome na modalidade falada, como vimos na seção 1 , destaca-se igualmente na escrita.

privilegiou textos de natureza mais narrativa e menos opinativa, como seria, por exemplo, o noticiário político, nos permitimos essa variação terminológica.

10 As reflexões e conclusões advindas dos estudos sobre referenciação estão reunidas em Roncarati (2010). 
A ordenação dos SPreps locativos e temporais ilustra igualmente a convergência na ação de princípios mais gerais que operam independentemente das diferentes condições de produção de cada uma das modalidades. Paiva et al. (2007) e Paiva (2008a, 2011, [20--]) discutem em detalhes a similaridade na forma como a ocorrência desses constituintes na margem esquerda da oração interage com a posição do sujeito (VS, SV). Além desse aspecto estrutural, outras similaridades se destacam, como as que decorrem da ação do princípio de peso final, particularmente na sequenciação relativa de circunstanciais de categorias semânticas distintas, como as de tempo, modo e lugar.

A segunda questão, a de princípios norteadores da incorporação, expansão ou retração de variantes inovadoras na escrita, encontra igualmente evidências na análise de alguns fenômenos variáveis, a exemplo dos estudados por Mollica (2003b, 2007, 2010, [20--]b), fenômenos que podem ser considerados como mudança em curso, como o uso das relativas cortadoras, o queísmo ou ainda a alternância entre muitas das vezes/muitas vezes. A título de hipótese, a autora postula que a maior chance de ingresso de estruturas queístas e relativas cortadoras na escrita se explica em termos do princípio segundo o qual estruturas menos marcadas (MOLLICA, 2010, [20--]b) possuem mais acolhida na escrita do que as formas linguísticas mais marcadas. O mesmo princípio pode justificar a forte resistência à introdução de muitas das vezes na escrita (MOLLICA, [20--]a), se considerarmos seu status mais marcado. A autora defende, ainda, a hipótese de que pressões relativas à regularização paradigmática e tendências resultantes do processo de hipercorreção intervêm igualmente na forma como a mudança opera, tanto na fala como na escrita.

Os estudos de variação na língua escrita têm mostrado, também, que há determinadas estruturas mais frequentes nessa modalidade, embora possam assumir diferentes roupagens, dependendo do gênero textual. Veja-se o caso da concordância verbal com SNs complexos (aqueles que contêm um SPrep encaixado), focalizada por Scherre e Naro (2007, [20--]). Os autores atestam, sobretudo, a importância de traços do sujeito na mudança do controle da concordância verbal ${ }^{11}$. Estabelecem uma escala que vai dos sujeitos mais fortes aos menos fortes, a partir de traços semânticos (caráter referencial, humano) e morfológicos (presença de expressões com numerais) e demonstram como isso pode influenciar no controle da regra de concordância verbal. ${ }^{12}$

11 No referido artigo, o corpus de escrita analisado não se restringe a jornais cariocas, mas abrange cartas circulares, ofícios, memorandos e textos técnicos ou científicos, todos tidos como monitorados. Os autores, porém, não fazem um controle específico dos gêneros utilizados.

12 Esse caso particular de concordância não pôde ser estudado na fala, uma vez que, nesta modalidade, ao menos no gênero entrevista sociolinguística, é muito rara a presença de SNs complexos. 
A forte presença de SNs complexos em gêneros da escrita jornalística e acadêmica tem sido escrutinada por Paredes Silva (2011), com o objetivo de verificar a correlação dos tipos de SNs com suas funções sintáticas e discursivas em diversos gêneros de escrita. Considerando aspectos estruturais como o número de constituintes do SN, o número e o tipo de Spreps encaixados, a presença de nominalizações, é possível identificar uma escala que situa SNs mais complexos em gêneros acadêmicos ${ }^{13}$ decrescendo a complexidade nos gêneros jornalísticos, conforme se trate de artigos de opinião, notícias e crônicas. Tais diferenças demonstram, claramente, que a possibilidade de compactar informações, graças a recursos como nominalizações se distribui de forma diferenciada num continuum escrito/oral.

As generalizações destacadas até este ponto emergiram em análises, sobretudo, da Amostra de Textos Midiáticos. O próprio interesse pela investigação do continuum fala - escrita, conduz, necessariamente, à exploração de gêneros intermediários, não contemplados na organização inicial do corpus jornalístico. A colocação de outras questões exigiu a análise de amostras como entrevistas transcritas em jornais e revistas (PAREDES SILVA; MARTINS, 2008), diálogos de revistas de quadrinhos (SCHERRE, 2008) assim como de redações de alunos. (MOLLICA et al, 2007).

Nessa expansão para novos locus de variação e mudança, ganham, ainda, destaque os estudos da linguagem do ciberespaço, utilizada nas redes sociais, moldada para atender aos relacionamentos virtuais assim como a veiculação de informação em plataforma de Ensino a Distância (EAD) (BARBOSA, 2010). Como mostra Mollica (2012), a comunicação via web configura um novo espaço de variação e mudança que pode, inclusive, abrir portas para a entrada de novas formas linguísticas variáveis na língua. Um exemplo é a forma orkutização, que tal como digitalização, constitui inovação. No entanto, não corresponde ao processo de orkutizar, estrutura verbal que nem entrou no português assim como *haqkear, diferentemente do verbo twitar, que teve entrada franca na língua. Abrem-se, assim, novas perspectivas para a verificação das questões centrais sobre contato linguístico, code-switching, redes sociais, formação do léxico e sobre mudança.

Retomando as questões levantadas no início desta seção, podemos dizer que:

a) Existe uma série de restrições aos fenômenos variáveis que se manifesta de forma similar na escrita e na fala. As diferenças no meio de produção podem, todavia, interferir na forma como essas restrições operam.

b) Mudanças em curso, que se instalam de forma mais veloz na fala, podem ser incorporadas na escrita. Algumas podem, no entanto, ser inibidas por força do poder conservador da norma e das instituições.

13 Foram investigados artigos, resumos de artigos e abstracts de dissertações e teses da área de Letras. 

c) À incorporação de mudanças na escrita subjazem princípios que, de certa forma, selecionam candidatos a serem incorporados.
d) Mesmo bons candidatos a serem incorporados na escrita obedecem a uma trajetória que envolve as distinções de gêneros textuais.

\section{Abrindo outras frentes de trabalho e colocando outras questões}

As questões relativas à variação e mudança na variedade carioca, nas suas modalidades falada e escrita, projetam outros questionamentos. Destacamos, nesta seção, as questões ligadas à aquisição da variação e às aplicações teóricometodológicas da pesquisa sociolinguística.

A aquisição da variação sociolinguística, focalizando o período que antecede a alfabetização formal, com crianças de 2 a 5 anos, é uma vertente que tem sido explorada recentemente no PEUL. Registre-se, no entanto, o trabalho pioneiro de Alzira Tavares de Macedo, em sua tese de doutorado "Uso do Futuro do Subjuntivo em Português: regularização de uma forma verbal", que além de um estudo de tempo aparente com dados de adultos também utilizou testes com crianças para avaliar os condicionamentos da variação na aquisição.

Estudos sobre aquisição da variação partem do pressuposto de que, se a variação é inerente ao sistema, as estruturas variáveis são adquiridas da mesma forma que as invariáveis (CHAMBERS, 1995). A observação da aquisição linguística sob o enfoque da Sociolinguística Variacionista tem permitido observar de que maneira os condicionamentos que regulam a variação na gramática estabilizada do adulto atuam na aquisição; como são transmitidos às crianças valores sociais associados a variantes; como se dá a aquisição de condicionamentos sociais; de que maneira a variabilidade manifestada pelas crianças reflete o estágio da mudança em curso. Ainda, como qualquer outro estudo dentro deste quadro de referência, os resultados sobre aquisição da variação devem contribuir para a discussão da modelagem teórica da variação na gramática.

Diversos trabalhos já foram realizados e dissertações e teses orientadas utilizando a Amostra AQUIVAR/PEUL/UFRJ, a saber: Gomes (2004), sobre a aquisição de complementos indiretos; Benayon (2006), sobre a aquisição de ditongos; Vieira (2006), sobre a flexão da $3^{a}$ pessoa do plural; Gomes (2006), sobre a aquisição da vibrante em coda; Gomes (2010), sobre a aquisição dos grupos consonantais formados por lateral (claro craro) e tepe (precisa picisa); Benayon (2010), sobre a aquisiç̧ão das fricativas; Gomes et al (2011), sobre a flexão nominal e a flexão verbal na aquisição.

Outros trabalhos discutem questões teóricas e metodológicas centrais no estudo da aquisição da variação, a saber: Gomes, Benayon e Vieira (2006), sobre 
a aquisição da variação sob a ótica dos modelos multirepresentacionais; Gomes (2008), sobre questões teóricas e metodológicas da variação na aquisição; Gomes (2011), sobre o papel da variação na modelagem do conhecimento fonológico na aquisição e no adulto. As evidências fornecidas por esses trabalhos têm contribuído para ampliar o conhecimento sobre a aquisição linguística e mostram a importância de se observar a aquisição dos aspectos variáveis da estrutura linguística.

Os estudos sobre aquisição da variação têm atestado a convergência entre princípios mais gerais que regulam a heterogeneidade estruturada na gramática do adulto e a forma como se processa a aquisição dos processos variáveis. No estudo da realização variável da marca de $3^{\mathrm{a}}$ pessoa do plural, por exemplo, Vieira (2006) observou o efeito relevante de saliência fônica, isto é, uma tendência à ausência de marca flexional naqueles verbos em que a diferença entre a forma de singular e plural é menor; ao contrário, maior presença de marcas flexionais nos casos em que a diferença é maior. A presença da marca de plural é mais evidente, para as crianças, nos três últimos níveis da escala proposta por Naro (1981).

Tomando como base a hipótese de que as representações sonoras se estabelecem em diferentes graus de abstração (PIERREHUMBERT, 2003), os trabalhos sobre aquisição de estruturas sonoras variáveis mostram a relação entre a importância das formas em competição - as variantes fonéticas - entendidas como parte da representação da forma das palavras e os tipos fonológicos que podem ser abstraídos destas representações, e em que níveis de abstração. A relação entre type (tipo) e token (ocorrência) permite não só compreender o percurso aquisitivo como também autoriza inferências sobre o conhecimento linguístico que está sendo abstraído. O estudo da aquisição dos grupos consonantais revelou, por exemplo, que a diferença na aquisição dos dois padrões silábicos, a saber: onset complexo formado por obstruinte e tendo como alvo a lateral, como em [globu] [grobu]; e obstruinte tendo como alvo o tepe, como em [outru] [outu], não pode ser explicada em função de uma hierarquia aquisitiva. Foi observado que os itens que têm a lateral como alvo utilizam ou manifestam a realização da segunda consoante do onset antes daqueles que têm o tepe como alvo. Algumas evidências provenientes destes diversos estudos mostram que não há, neste caso, a atuação de uma hierarquia aquisitiva, em que alguns sons são adquiridos antes de outros, com reflexos na aquisição dos itens que possuem essas estruturas. Houve crianças que apresentaram alta incidência de tepe e lateral no onset complexo do tipo $\mathrm{C}(\mathrm{r}) \mathrm{V}$, mas ausência de tepe em onset, sendo este substituído por lateral e vice-versa, isto é, apresentaram ausência da segunda consoante no grupo e presença da líquida no onset. Esse padrão de aquisição é atribuído à competição entre formas fonéticas e os tipos estruturais a eles subjacentes. No caso da variação entre lateral e tepe, essa alternância não 
implica competição de padrões fonológicos diferentes, favorecendo a abstração de um padrão CCV para os itens que se enquadram neste caso (GOMES, 2010).

Do ponto de vista da aplicação, a grande massa de material produzido sobre a variedade carioca garantiu o conhecimento do perfil sociolinguístico dessa comunidade de fala e forneceu as condições ótimas para repensar a forma de traduzir o produto das pesquisas produzidas em subsídios para a educação. Assim, desde o início dos anos 90, a pesquisadora Maria Cecília Mollica tem se dedicado a uma vertente de estudos - Sociolinguística Educacional - cuja preocupação central é a criação e disponibilização de material instrucional (na forma de livros e CDs) que incorpora a variação fono-ortográfica, morfossintática e discursiva. Contribui, ainda, para a formação continuada de docentes em vários níveis de ensino. (MOLLICA, 2000, 2003a, 2006, 2007, 2009; RONCARATI; MOLLICA, 2001).

Estes trabalhos partem do pressuposto de que o conhecimento da realidade sociolinguística das comunidades de fala permite analisar os problemas específicos dos aprendizes e conhecer as dificuldades próprias dos docentes em via de qualificação, a fim de melhor instrumentalizá-los para lidar com a natureza heterogênea da linguagem e seus diferentes registros escritos. Tal pressuposto é primordial também quando se tem a meta precisa de se oferecer soluções para questões importantes e atinentes à alfabetização e ao letramento em todo o seu percurso. A parceria com pesquisadores da área de Matemática tem permitido estender as reflexões para questões relativas à escrita matemática (LEAL; MOLLICA, 2009, 2010, [20--]). A proposta de estratégias de mediação vem se mostrando eficaz na implementação de pedagogia que lida com fenômenos dinâmicos em classes muito heterogêneas sociolinguisticamente, em ambientes institucionalizados ou não institucionalizados. Neste particular, tem sido profícuo o esforço em oferecer subsídios aos alfabetizadores que participam do Programa de Alfabetização da UFRJ cujo objetivo é o de melhor qualificar os docentes para atuar de forma eficaz ao entender e explicar os erros na produção discursivotextual dos noviços em processo de alfabetização e letramento.

Nesta perspectiva da Sociolinguística Educacional se inserem, ainda, os estudos sobre o contato entre comunidades geograficamente diferentes, rurais ou urbanas, que levam em conta os continua de níveis de oralidade e escrita, de monitoramento estilístico e de práticas eminentemente orais comparadas a eventos de letramento (MOLLICA, 2003a; MOLLICA; LEAL, 2008, 2010), bem como suas repercussões para a prática docente e discente.

O mais recente desafio nesta linha de investigação encontra-se em trabalho inédito de Mollica e Roncarati ([20--]) em que as autoras lançam mão de alguns princípios funcionalistas, com vistas a instrumentalizar o professor para melhor trabalhar pedagogicamente com a variação. Para tanto, focalizam conceitos como 
arbitrariedade e iconicidade, estatuto informacional do referente, cadeia tópica e parâmetros tais como saliência fônica, marcação, regularização paradigmática, níveis de acessibilidade do referente, com o objetivo de oferecer explicação nova aos docentes em processo de capacitação ${ }^{14}$.

A atuação de alguns pesquisadores do PEUL como docentes do curso de Fonoaudiologia da UFRJ vem gerando frutos interessantes para a compreensão, sob a ótica da Sociolinguística, dos quadros de transtornos de aprendizagem das habilidades de leitura e escrita e da escrita matemática (MOLLICA; SILVA, [20--]). Para tanto, a pesquisadora tem estabelecido parceria estreita com professora Marisa Leal (IM/UFRJ) com quem vem pesquisando e orientando trabalhos em literacia nos campos de linguagem e matemática especialmente voltados para a educação de jovens e adultos - EJA (LEAL; MOLLICA, 2009, 2010, [20--]). Nesse particular, tem sido profícuo seu esforço em oferecer subsídios aos alfabetizadores que participam do Programa de Alfabetização da UFRJ, cujo objetivo é o de melhor qualificar os docentes para atuar de forma eficaz ao entender e explicar os erros na produção discursivo-textual dos noviços em processo de alfabetização e letramento.

A exploração das interfaces da Sociolinguística com outras áreas de conhecimento têm se mostrado igualmente instigante na colaboração com profissionais de Ciência da Informação. Um bom exemplo dos resultados dessa parceria é o trabalho de Guedes (2010), que comprova a regularidade da variação de sufixos em nominalizações deverbais em periódicos científicos. A autora utiliza as leis de ZIPF, de 1935, de modo a verificar a zona de maior densidade semântica das formas variáveis. Na mesma direção, a pesquisadora identifica as diferenças estatísticas da variação no continuum fala/escrita (GUEDES, 2010, 2012) e analisa a escrita do gênero resumos de cartas científicas, que circulavam entre filósofos naturais desde o século XVII, desempenhando papel crucial na comunicação científica. Os resultados encontrados pela autora contribuem para estabelecer pontos de interação entre a Linguística e a indexação na Ciência da Informação.

\section{Considerações finais}

Neste artigo, ressaltamos alguns pontos que constituíram a pauta central de trabalho do grupo PEUL, com ênfase nas questões teóricas e metodológicas ligadas à dinamicidade inerente das línguas naturais. Ressaltaram-se, ainda, os caminhos possíveis que a Sociolinguística pode trilhar na interface com outras áreas da Ciência, abrindo, assim, o espaço para maior compreensão dos múltiplos usos da língua.

14 A pesquisadora tem envidado esforços tanto no sentido de fornecer subsídios para o processo de letramento de sujeitos típicos como de sujeitos com desenvolvimento atípico, o que se torna possível graças à parceria com profissionais da área de Fonoaudiologia. Essa parceria vem gerando frutos para a compreensão dos quadros de transtornos de habilidades de leitura e de escrita matemática. 
PAIVA, M. C. de; PAREDES SILVA, V. L. Fulfilling a Working Agenda. Alfa, São Paulo, v.56, n.3, p.729-760, 2012.

- ABSTRACT: PEUL (Program for the Study of Language Use) is composed of a group of researchers whose main initial purpose is to investigate patterns of variation and change in Brazilian Portuguese as spoken in Rio de Janeiro (the "carioca" variety). At first, in the 1980 's, only spoken language was studied. A new sample of the same community of speakers collected about 20 years later facilitated comparison of the behavior of the community (trend study) and the individuals (panel study). These studies gave rise to the analysis of linguistic change in real time. Recently, investigation of written language, focusing specifically on newspaper genres, has been undertaken. This expansion of both aims and corpora was motivated by comparison of principles correlated to variable phenomena in the modalities under investigation. It also allowed verification of hypotheses related to the migration of change-in-process from spoken to written language. In this article we intend to show how the analysis developed by members of the group has contributed to deepen several relevant theoretical points. The systematicity of principles underlying the variable use of distinct phenomena, the way linguistic change penetrates written genres, or is rejected by them, are some of the issues presented. The constant examination of new questions has expanded research to the interface with other areas of knowledge.

- KEYWORDS: SociolinguisticS. Spoken language. Written language. Text genre. Applications.

\section{REFERÊNCIAS}

ALMEIDA, M. C.; RONCARATI, C. N. A multifuncionalidade da clivagem na fala e na escrita. Revista Linguística, Rio de Janeiro, n.7, v.1, p.21-52, 2007.

BAKHTIN, M. Estética da criação verbal. São Paulo: Martins Fontes, 2003.

BARBOSA, M. F. S. de O. (Im)polidez em EAD. 2010. 136f. Tese (Doutorado em Linguística) - Faculdade de Letras, Universidade Federal do Rio de Janeiro, Rio de Janeiro, 2010.

BENAYON, A. R. Aquisição das fricativas sibilantes no português brasileiro: propriedades distribucionais e variação. 2010. 138f. Tese (Doutorado em Linguística) - Faculdade de Letras, Universidade Federal do Rio de Janeiro, Rio de Janeiro, 2010.

A emergência de padrões fonológicos: a aquisição de ditongos orais decrescentes do PB. 2006. 138f. Dissertação (Mestrado em Linguística) - Faculdade de Letras, Universidade Federal do Rio de Janeiro, Rio de Janeiro, 2006.

BRAGA, M. L. E aí se passaram 19 anos. In:DUARTE, M. E. L. Mudança linguística em tempo real. Rio de Janeiro: Contra Capa: Faperj, 2003. p.159-174.

BRAGA, M. L. et al. É um problema de visão para perto, inevitável após os 40 anos de idade, onde o indivíduo tem dificuldade para ver imagens. Revista Linguística, Rio de Janeiro, v.3, n.1, p.117-132, 2007. 
BRAGA, M. L.; MOLLICA, M. C. M. As estruturas, SN pleno + SN pronominal anafórico no português do Brasil 20 anos depois. In: LIMA-HERNANDES, M. C.; CHULATA, K. A. Língua portuguesa em foco: ensino-aprendizagem, pesquisa e tradução. Lecce: Pensa Multimidia, v.1, 2010. p.85-95.

BRAGA, M. L.; PAIVA, M. C. A. Gramaticalização e sociolinguística variacionista: o tratamento das construções iniciadas por por. In: LIMA, M. A. F. et al. Colóquios linguísticos e literários: enfoques epistemológicos, metodológicos e descritivos. Teresina: Ed. da UFPI, 2011a. p.125-152.

Gramaticalização e gramática de construções: estabilidade e instabilidade no uso de orações complexas de causa em tempo real. Revista Letras \& Letras, Uberlândia, v.27, n.1, p.51-70, 2011b.

COSTA, A. L. dos P. O futuro do pretérito e suas variantes no português do Rio de Janeiro: um estudo diacrônico. 2003. 132f. Tese (Doutorado em Linguística) Faculdade de Letras, Universidade Federal do Rio de Janeiro, 2003.

CHAMBERS, J. Sociolinguistic Theory. Oxford: Blackwell, 1995.

CROFT,W. Typology and universals. Cambridge: Cambridge University Press, 1990.

CYRINO, S. O objeto nulo no português do Brasil: um estudo sintático-diacrônico. Londrina: Ed. da UEL, 1997.

CYRINO, S.; DUARTE, M. E.; KATO, M. A. Visible subjects and invisible clitics in Brazilian Portuguese. In: KATO, M. A.; NEGRAO, E. V. (Ed.). Brazilian Portuguese and the Null Subject Parameter. Frankfurt-Madrid: Vervuert-Iberoamericana, 2000. p.55-104.

DRYER, M. S. Frequency and pragmatically unmarked word order. In: DOWNING, P.; NOONAN, M. (Ed.). Word Order in Discourse. Amsterdan: John Benjamins, 1995. p.105-135.

DUARTE, M. E. L. A representação dos sujeitos de "referência estendida": um estudo diacrônico. In: LOBO, T. et al. (Org.). ROSAE: linguística histórica, história das línguas e outras histórias. Salvador: Ed. da UFBA, 2012. p.123-135.

Sujeitos de referência definida e arbitrária: aspectos conservadores e inovadores na escrita padrão. Revista Lingüística, Rio de Janeiro, v.3, n.1, p.89$115,2007 b$.

A evolução na representação do sujeito em dois tempos. In: PAIVA, M. C.; DUARTE, M. E. L. Mudança linguística em tempo real. Rio de Janeiro: Contra Capa, 2003a. p.115-128. 
. O sujeito expletivo e as construções existenciais. In. RONCARATI, C.; ABRAÇADO, J. (Org.). Português Brasileiro: contato linguístico, heterogeneidade e história. Rio de Janeiro: 7Letras, 2003b. p.123-131.

.The loss of avoid pronom in brazilian Portuguese. In: KATO, M. A; NEGRÃO.

E. V. In: Brasilian Portuguese and the null subject. Frankfurt am Main:Vervuert: Verlag, 2000, p.17-36.

A perda do princípio 'Evite pronome' no português brasileiro. 2005. $140 f$. Tese (Doutorado) - Universidade de Campinas, Campinas, 1995.

DUARTE, M. E. L.; FREIRE, G. C. Como a escrita padrão recupera formas em extinção e implementa formas inovadoras In: PAIVA, M. A.; GOMES, C. A. (Org.). A dinâmica da variação e mudança na escrita. [20--]. No prelo.

GIVON, T. Syntax: a functional typological introduction. Amsterdan: John Benjamins Publishing, 1990. v.II.

GOMES, C. A. Uso variável do dativo na escrita jornalística. In: PAIVA, M. C. A; GOMES, C. A. Dinâmica da variação e da mudança na escrita. [20--]. No prelo.

. Variação sociofonética na aquisição e na modelagem do conhecimento linguístico. Revista da ABRALIN, Brasília, v.2, p.209-226, 2011.

Variação linguística e aquisição do onset complexo no português brasileiro. In: MOLLICA, M. C. de M. (Org.). Usos da linguagem e sua relação com a mente humana. Rio de Janeiro: Tempo Brasileiro, 2010. p.15-22.

. Aquisição da variação estruturada: uma nova perspectiva de pesquisa. In: VOTRE, S.; RONCARATI, C. (Org.). Anthony Julius Naro e a linguística no Brasil uma homenagem acadêmica. Rio de Janeiro: 7 Letras: FAPERJ, 2008. p.107-114.

. Uso variável do dativo na fala e na escrita. Revista Linguística, Rio de Janeiro, v.3, n.1, p.7-20, 2007.

. Aquisição do tipo silábico CV(r) no português brasileiro. Scripta, Belo Horizonte, v.10, p.58-77, 2006.

. Aquisição linguística em contexto de input variável: a emergência das variantes de dativo. Revista de Estudos da Linguagem, Belo Horizonte, v.12, n.1, p.175-190, 2004.

Variação e mudança na expressão do dativo no português brasileiro. In: PAIVA, M. C.; DUARTE, M. E. L. Mudança linguística em tempo real. Rio de Janeiro: Contra Capa: Faperj, 2003. p.81-96.

GOMES, C. A.; BENAYON,A. R.; VIEIRA, M. C. P. Aquisição linguística sob a ótica dos modelos multirepresentacionais. Gragoatá, Niterói, v.21, p.303-318, 2006. 
GOMES, C. A. et al. Variação e aquisição de flexão nominal e flexão verbal. Gragoatá, Niterói, v. 30, p.39-54, 2011.

Pressões estruturais e discursivas no condicionamento da variação: a ordem dos complementos verbais no português brasileiro. In: RONCARATI, C.; ABRAÇADO, J. (Org.). Português brasileiro: contato linguístico, heterogeneidade e história. Rio de Janeiro: 7 Letras, 2003. p.199-205.

GRYNER, H. Equilíbrio e desequilíbrio na evolução das estruturas condicionais. In: DUARTE, M. E. L. Mudança linguística em tempo real. Rio de Janeiro: Contra Capa : Faperj, 2003. p.175-192.

A variação de tempo, modo e conexão nas orações subordinadas condicionais do português. 1990. 550f. Tese (Doutorado em Linguística) Universidade Federal do Rio de Janeiro, Rio de Janeiro, 1990.

GUEDES, V. L. S. Breve histórico do artigo de periódico. In: MOLLICA, M. C. M. (Org.). Linguística e Ciência da Informação: diálogos possíveis. Rio de Janeiro: APPRIS, 2012.

Nominalizações deverbais em artigos científicos: uma contribuição para a análise e a indexação temática da informação. 2010. 107f. Tese (Doutorado em Linguística) - Faculdade de Letras, Universidade Federal do Rio de Janeiro, Rio de Janeiro, 2010.

LABOV, W. Sociolinguistic Patterns. Philadelphia: University of Pennsylvania Press, 1972.

. Principles of linguistic change: internal factors. Cambridge: Blackwell, 1994.

Building on empirical foundations. In: LEHMANN,W.; MALKIEL, Y. (Ed.). Perspectives on historical linguistics. Amsterdam: John Benjamins, 1982. p.17-92.

What can be learned about change in progress from synchronic descriptions. In: SANKOFF, D.; CEDERGREN, H. (Ed.). Variation Omnibus. Carbondale; Edmonton: Linguistic Research, 1981. p.177-199.

LEAL, M.; MOLLICA, M. C. Lendo matemática. In: BORTONI-RICARDO, S. M. Mediação em leitura. São Paulo: Parábola Editorial, [20--?].

. Competências subjacentes à leitura: pilares de acesso saberes formais. In: . (Org.). Construindo o capital formal das linguagens. Curitiba: CRV, 2010. . Letramento em EJA. São Paulo: Parábola Editorial, 2009.

LIGHTFOOT, D. The development of language acquisition, change and evolution. Oxford: Blackwell, 1999. 
MARTINS, K. C. A expressão variável de anterioridade a um ponto de referência passado na escrita midiática. 2010. 131f. Dissertação de mestrado (Mestrado em Linguística) - Universidade Federal do Rio de Janeiro, Rio de Janeiro, 2010.

MILROY, L. Language and social networks. Language in society 2. Oxford: Blackwell, 1980.

MOLLICA, M. C. Primeiras notas sobre muitas das vezes. In: PAIVA, M. C.; GOMES, C. A. (Org.). Dinâmica da variação e mudança na escrita. [20--]a. No prelo.

. Sobre restrições de mudança linguística. In: Congresso de la Delegación Argentina de la Asociación de Filologia de América Latina, 1., [20--]b, La Plata. Atas... La Plata: Faculdad de Humanidades y Ciencias de la Educación, Universidad Nacional de La Plata, [20--]b. No prelo.

Neologismos na era cibernética. In: PEREIRA, J. Neologia e neologismo no Brasil. Curitiba: Primas, 2012. p.277-288.

. Mudança e resistência no contínuo oral/escrito. In: MOLLICA, M. C. (Org.). Usos da linguagem e sua relação com a mente humana. Rio de Janeiro: Edições Tempo Brasileiro, 2010. p.91- 97.

. Formação em linguagem. In: (Org.). Linguagem para a formação em letras, educação e fonoaudiologia. São Paulo: Contexto, 2009. p.27-33.

Aportes para uma teoria da mudança na escrita. In: VOTRE, S.; RONCARATI, C. Anthony Julius Naro e a Linguística no Brasil: uma homenagem acadêmica. Rio de Janeiro: FAPERJ : 7LETRAS, 2008. p.242-53.

Da escola para vida: a importância do letramento escolar. Acolhendo a alfabetização nos países de Língua Portuguesa. São Paulo: Ed. da USP, 2007. p.19-30.

. Português e matemática: parceria indispensável em política educacional. In: SILVA, C. R.; DA HORA, D.; CHRISTIANO, M. E. (Org.). Linguística e práticas pedagógicas. Santa Maria: Pallotti, 2006. p.33-54.

. Da linguagem coloquial à escrita padrão. Rio de Janeiro: 7LETRAS, 2003a.

. Relativas em tempo real no português brasileiro contemporâneo. In: PAIVA, M. C.; DUARTE, M. E. Mudanças linguísticas em tempo real. Rio de Janeiro: Contra Capa, 2003b. p.129-138.

. Influência da fala na escrita. Rio de Janeiro: Edições Tempo Brasileiro, 2000.

MOLLICA, M. C. et al. Marcas de fala na escrita de jornal e de escola. Revista Linguística, Rio de Janeiro, v.3, n.1. p.53-68, 2007b. 
MOLLICA, M. C.; GONÇALEZ, M. Linguística e Ciência da Informação: diálogos possíveis. Curitiba: APPRIS, 2012.

MOLLICA, M. C.; LEAL, M. Ler e interpretar informação. In: MOLLICA, M. C.; GONZALEZ. Lingüística e Ciências da Informação: diálogos possíveis. Curitiba: APPRIS, 2012. p.201-209.

Modos de Ancoragem na interpretação da leitura de algumas bulas e listas. Revista Domínios de Lingu@gem, Uberlândia, ano 4, n.1, p.115-130, 2010.

Oralidades em linguagens. In: GONÇALVES, C. A; ALMEIDA, M. L. L. (Org.). Língua portuguesa: identidade, difusão e variabilidade. Rio de Janeiro: AILP : UFRJ, 2008. v.2. p.493-502.

Letramentos na escola e na vida. In: SILVEIRA, M. L. S. (Org.). Educação popular e leituras do mundo. Rio de Janeiro: UFRJ, 2007. p.35-42.

MOLLICA, M. C.; LISBÔA, S. G. Produtividade lexical em artigos científicos e a indexação temática da informação. In: SOARES, A et al. Línguas pluricêntricas: variação linguística e dimensões sociocognitivas. Braga: Universidade Católica Portuguesa, 2011. p.393-408.

MOLLICA, M. C.; RONCARATI, C. Como a escola pode explicar erros gramaticais e inovações? In: BORTONI-RICARDO, S. M. Por que a escola não explica assim? São Paulo: Parábola Editorial. [20--]. No prelo.

MOLLICA, M. C.; SILVA, P. O letramento de sujeitos típicos e atípicos. São Paulo: Contexto, [20--]. No prelo.

NARO, A. J. Sobre o efeito do princípio da saliência na concordância verbal na fala moderna, na escrita antiga e na escrita moderna. In: MOURA, D.(Org.). Os múltiplos usos da língua. Maceió: Ed. da UFAL, 1999. p.26-37.

The social and structural dimensions of a syntactic change. Language, Baltimore, n.57, p.63-98, 1981.

NARO, A. J.; SCHERRE, M. A trend study revisited: remodeling the age variable in number concord in Brazilian Portuguese. Washington: Georgetown University, 2011. Comunicação apresentada no Congresso NWAV40.

Fluxos e contrafluxos: movimentos sociolingüísticos da comunidade de fala brasileira. In: MOLLICA, M. C (Org.). Usos da linguagem e sua relação com a mente humana. Rio de Janeiro: Tempo Brasileiro, 2010. p.79-90.

Estabilidade e mudança linguística em tempo real: a concordância de número. In: PAIVA, M. C.; DUARTE, M. E. (Org.). Mudança em tempo real. Rio de Janeiro: Contra Capa: Faperj, 2003. p.47-62. 
OLIVEIRA SILVA, G. M.; SCHERRE, M. M. P. Padrões sociolinguísticos: análise de fenômenos variáveis do português falado no Rio de Janeiro. Rio de Janeiro: Tempo Brasileiro, 1996.

OMENA, N. P. de. A referência à primeira pessoa do plural: variação ou mudança? In: PAIVA, M. C.; DUARTE, M. E. L. (Org.). Mudança linguística em tempo real. Rio de Janeiro: Contra Capa : Faperj, 2003. p.63-80.

PAIVA, M. C. Restrições à posição de SPreps temporais na modalidade falada. Alfa, São Paulo, v.56, n.1, p.29-53, 2012.

Configurações XSV eXVS no português contemporâneo: complemantaridade sintático-semântica e discursiva. Diadorim, Rio de Janeiro, n.8, p.245-270, 2011.

. Ordem não marcada de circunstanciais locativos e temporais. In:VOTRE, S.; RONCARATI, C. (Org.). Anthony Naro e a linguística no Brasil: uma homenagem acadêmica. Rio de Janeiro: 7 Letras, 2008a. p.254-264.

. A ordem de circunstanciais no português brasileiro escrito. Diacrítica, Braga, v.22, n.1, p.73-91, 2008b.

O percurso da monotongação de [ey]: observações no tempo real.. In: PAIVA, M. C. A.; DUARTE, M. E. L. Mudança linguística em tempo real. Rio de Janeiro: Contra Capa: Faperj, 2003. p.31-46.

Gramaticalização de conectores no português do Brasil. Scripta, Belo Horizonte, v.5, n.9, p.35-46, 2001.

Ordenação de circunstanciais na escrita: princípios em competição? In: PAIVA, M. C. A; GOMES, C. A (Org.). Dinâmica da variação e da mudança na escrita. [20--]. No prelo.

PAIVA, M. C.; BARROS, E. C. M. Construções modais com ter: gramaticalização e variação. Diacrítica, Braga, v.25, n.1, p.259-282, 2011.

PAIVA, M. C.; DUARTE, M. E. L. Introdução. In: Mudança linguística em tempo real. Rio de Janeiro: ContraCapa: Faperj, 2003. p.13-30.

PAIVA, M. C. A; GOMES, C. A (Org.). Dinâmica da variação e da mudança na escrita. [20--]. No prelo.

PAIVA, M. C.; SCHERRE, M. M. P. Retrospectiva sociolinguística: contribuições do PEUL. D.E.L.T.A, São Paulo, v.15, n. especial, p.201-222, 1999.

PAIVA, M. C. et al. Extensão e posição de circunstanciais temporais. Cadernos do CNLF, Rio de Janeiro, v.13, n.4, p.1880-1891, 2009. 
Padrão não marcado de ordenação de circunstancias temporais: regularidades e divergências entre fala e escrita. Revista Linguística, Rio de Janeiro, v.1, n.3, p.69-88, 2007.

PAREDES SILVA, V. L. P. É isso aí: verbo ser e demonstrativos em função coesiva no português. In: ENCONTRO NACIONAL DE LINGUÍSTICA, 10., 1985, Rio de Janeiro. Anais... Rio de Janeiro: PUC-RJ, 1985. Mimeografado.

. Cartas cariocas: a variação do sujeito na escrita formal. 1988. 330f. Tese (Doutorado em Linguística) - Faculdade de Letras, Universidade Federal do Rio de Janeiro, Rio de Janeiro, 1988.

. O retorno do pronome tu à fala carioca. In: RONCARATI, C.; ABRAÇADO, J.. (Org.). Português brasileiro: contato linguístico, heterogeneidade e história. Rio de Janeiro: FAPERJ: 7Letras, 2003a. p.160-169.

Motivações funcionais no uso do sujeito pronominal: uma análise em tempo real. In: PAIVA, M. C.; DUARTE,M. E. L. (Org.). Mudança linguística em tempo real. Rio de Janeiro: Contra Capa: Faperj, 2003b. p.97-114.

O uso da anáfora zero em textos jornalísticos. Cadernos de Pesquisa em Linguística, Porto Alegre, v.3, n.1, p.52-61, 2007a.

. Continuidade de referência: Nomes, pronomes e anáfora zero em gêneros da fala e da escrita. Revista Linguística, Rio de Janeiro, v.1, n.3, p.159-178, 2007b.

Desfazendo um mito: a repetição na escrita e suas funções. In: RONCARATI, C; ABRAÇADO, J. (Org.). Português brasileiro: contato linguístico, heterogeneidade e história. Niterói: Ed. da UFF, 2008a. p.334-344.

Ainda sobre sujeitos pronominais e flexão verbal: revisitando Naro. In: VOTRE, S.; RONCARATI, C. (Org.). Anthony Naro e a linguística no Brasil: uma homenagem acadêmica. Rio de Janeiro: 7 Letras, 2008b. p.381-392

Notícias recentes da presença do pronome tu no quadro de pronomes no português falado no Rio de Janeiro. In: REBOLLO COUTO, L.; LOPES, C. R. (Org.). As formas de tratamento no português e no espanhol. Variação, mudança e funções conversacionais. Niterói: Ed. da UFF, 2011. p.245-262.

O uso de sintagmas nominais complexos em gêneros jornalísticos e acadêmicos. Palestra apresentada no Curso de Pós-Graduação em Educação da Universidade do Minho, Braga, jun./2011. 17p. Mimeografado.

PAREDES SILVA, V. L. P. ; COSTA PINTO, P. I. A crônica: um gênero de vários tipos textuais. In: MOLLICA, M. C. (Org.). Usos da linguagem e sua relação com a mente humana. Rio de Janeiro: Tempo Brasileiro, 2010. p.37-52. 
PAREDES SILVA, V. L.; MARTINS, A. P. O uso de SNs definidos vs. demonstrativos como rótulos em entrevistas jornalísticas. Revista Linguística, Rio de Janeiro, v.4, n.1, p.39-58, 2008.

PAREDES SILVA, V. L.; OLIVEIRA, A. "É isso aí": a variação na referência estendida em diferentes gêneros de escrita. In: PAIVA, M. C.; GOMES, C. A. (Org.). Dinâmica da variação e mudança na escrita. [20--]. No prelo.

PIERREHUMBERT, J. Probabilistic phonology: discrimination and Robustness. In: BOD, R. et al. (Ed.). Probabilistic Linguistics. Boston: MIT Press, 2003. p.177-228.

RONCARATI, C. Os mostrativos na fala carioca. In: DUARTE, M. E. L. Mudança linguística em tempo real. Rio de Janeiro: Contra Capa: Faperj, 2003. p.139-158.

. Dêixis social - a designação social referenciada: sabe com quem você está falando? In:VOTRE, S. J.; RONCARATI, C. Anthony Naro e a linguística no Brasil: uma homenagem acadêmica. Rio de Janeiro: 7Letras: Faperj, 2008. p.115-147.

A subjetividade do demonstrativo na mídia jornalística. Investigações, São Paulo, v.21, p.221-240, 2009. 2010.

. As cadeias do texto - construindo sentidos. São Paulo: Parábola Editorial,

RONCARATI, C.; MOLLICA, M. C. Questões teórico-descritivas em Sociolinguística e em Sociolinguística aplicada: uma agenda de trabalho. D.E.L.T.A., São Paulo, v. 17, p.45-55, 2001.

SANTOS, G. M. O uso de pronomes pessoais genéricos no discurso argumentativo oral. 2003. 79f. Dissertação (Mestrado em Linguística) - Faculdade de Letras, Universidade Federal do Rio de Janeiro, Rio de Janeiro, 2003.

SCHERRE, M. M. P. Efeitos da saliência fônica e do tempo/modo na concordância verbal. In: MOLLICA, M. C. (Org.). Usos da linguagem e sua relação com a mente humana. Rio de Janeiro: Tempo Brasileiro, 2010. p.71-77.

. Paralelismo linguístico. Revista de Estudos da Linguagem, Belo Horizonte, v.7, n.2, p.29-59, jul./dez. 1998.

O imperativo gramatical no português brasileiro: reflexo de mudança na escrita de revistas em quadrinhos. In: VOTRE, S.; RONCARATI, C. Anthony Julius Naro e a linguística no Brasil: uma homenagem acadêmica. Rio de Janeiro: 7Letras, 2008. p.306-319.

SCHERRE, M. M. P; NARO,A. J. Sobre o deslocamento do controle da concordância verbal. In: PAIVA, M. C. A; GOMES, C. A. Dinâmica da variação e da mudança na escrita. [20--]. No prelo. 
. A panel study revisited: interpreting increase in use of number concord in Brazilian Portuguese. Washington: Georgetown University, 2011. Comunicação apresentada no Congresso NWAV40.

. O deslocamento do controle da concordância verbal. Revista Linguística, Rio de Janeiro, v.3, n.1, p.133-158, jun. 2007.

Marking in discourse. Birds of a feather. Language Variation and Change, Cambridge, v.3, n.1, p.23-32, 1992.

SCHERRE, M. M. P.; RONCARATI, C. Programa de estudos sobre o uso da língua (PEUL): origens e trajetórias. In:VOTRE, S.; RONCARATI, C. Anthony Julius Naro e a linguística no Brasil: uma homenagem acadêmica. Rio de Janeiro: 7Letras, 2008. p.37-49.

TESCH, L. M. A expressão do tempo futuro no uso capixaba: variação e gramaticalização. 2011. 191f. Tese (Doutorado em Linguística) - Faculdade de Letras, Universidade Federal do Rio de Janeiro, Rio de Janeiro, 2011.

VIEIRA, M. C. P. A emergência do padrão flexional variável de 3a pessoa do plural na aquisição do PB como L1. 2006. 120f. Dissertação (Mestrado em Linguística) Faculdade de Letras, Universidade Federal do Rio de Janeiro, Rio de Janeiro, 2006.

WEINREICH, U; LABOV, W; HERZOG, M. Fundamentos empíricos para uma teoria da mudança linguística. Tradução de Marcos Bagno. São Paulo: Parábola Editorial, 2006.

Empirical foundations for a theory of language change. In: LEHMANN, W.; MALKIEL, Y. (Ed.). Directions for historical linguistics. Austin: University of Texas Press, 1968. p.97-195.

Recebido em abril de 2012.

Aprovado em julho de 2012. 